\title{
Role of $\mathrm{N}$-terminal protein formylation in central metabolic processes in Staphylococcus aureus
}

\author{
Diana Mader ${ }^{1}$, Manuel Liebeke ${ }^{2,4}$, Volker Winstel ${ }^{1}$, Karen Methling ${ }^{2}$, Martina Leibig ${ }^{3}$, Friedrich Götz ${ }^{3}$, \\ Michael Lalk ${ }^{2}$ and Andreas Peschel ${ }^{1 *}$
}

\begin{abstract}
Background: Bacterial protein biosynthesis usually depends on a formylated methionyl start tRNA but Staphylococcus aureus is viable in the absence of Fmt, the tRNA ${ }^{\text {Met }}$ formyl transferase. fmt mutants exhibit reduced growth rates indicating that the function of certain proteins depends on formylated $\mathrm{N}$-termini but it has remained unclear, which cellular processes are abrogated by the lack of formylation.

Results: In order to elucidate how global metabolic processes are affected by the absence of formylated proteins the exometabolome of an S. aureus fmt mutant was compared with that of the parental strain and the transcription of corresponding enzymes was analyzed to identify possible regulatory changes. The mutant consumed glucose and other carbon sources slower than the wild type. While the turnover of several metabolites remained unaltered fmt inactivation led to increases pyruvate release and, concomitantly, reduced pyruvate dehydrogenase activity. In parallel, the release of the pyruvate-derived metabolites lactate, acetoin, and alanine was reduced. The anaerobic degradation of arginine was also reduced in the fmt mutant compared to the wild-type strain. Moreover, the lack of formylated proteins caused increased susceptibility to the antibiotics trimethoprim and sulamethoxazole suggesting that folic acid-dependant pathways were perturbed in the mutant.
\end{abstract}

Conclusions: These data indicate that formylated proteins are crucial for specific bacterial metabolic processes and they may help to understand why it has remained important during bacterial evolution to initiate protein biosynthesis with a formylated tRNA ${ }^{\text {Met }}$.

Keywords: Protein formylation, Bacterial metabolism, Staphylococcus, pyruvate dehydrogenase

\section{Background}

The start of protein biosynthesis with a formylated methionine represents a distinct bacterial feature that is absent in eukaryotes [1,2]. The ubiquitous presence in all bacterial branches including mitochondria and chloroplast indicates a very important role of this trait in central bacterial cellular processes but it has remained unclear, which bacterial proteins depend on $\mathrm{N}$-formylation for correct function. Nevertheless, it has become clear that formylation of the initiator tRNA is not essential for viability in some bacteria including Staphylococcus aureus where inactivation of

\footnotetext{
* Correspondence: andreas.peschel@uni-tuebingen.de

'Interfaculty Institute of Microbiology and Infection Medicine Tübingen, Cellular and Molecular Microbiology, University of Tübingen, Elfriede-Aulhorn-Straße 6, 72076, Tübingen, Germany

Full list of author information is available at the end of the article
}

the formyl transferase Fmt only leads to reduced growth and fitness [3,4].

The production of formylated proteins is potentially detrimental for bacterial pathogens because formylated peptides are sensed by mammalian innate immune systems leading to altered host defense and inflammation [5]. The human formyl peptide receptor FPR1 expressed on neutrophils and other leukocytes elicits neutrophil chemotaxis and activation upon ligand binding [6]. We have recently shown that formylated peptides represent crucial bacterial pathogen-associated molecular patterns [7] and that increased production of formylated peptides by inhibition of the deformylation reaction can increase proinflammatory reactions [8]. Of note, S. aureus secretes CHIPS, a potent inhibitor of FPR1 to interfere with immune activation [9].

The methionyl group of the bacterial start tRNA is modified by Fmt using formyl tetrahydrofolic acid

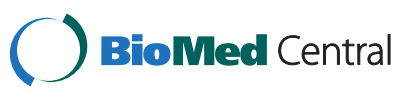


(formyl-THF) as the formyl group donor [10]. FormylTHF can be regenerated by different pathways among them the utilization of free formate in $S$. aureus produced by fermentation under anaerobic conditions [11]. The formyl group is removed from many proteins upon translation by polypeptide deformylase and this reaction is essential because the function of many proteins appears to depend on deformylated N-termini [12]. Accordingly, deformylase represents an attractive target for antibiotics [13]. Deformylase modifies only proteins with certain sequence motifs next to formylmethionine while those with unfavorable $\mathrm{N}$-terminal sequences remain unmodified [14]. The severe growth defect of Fmt mutants indicates that many bacterial proteins are fully functional only if the $\mathrm{N}$-terminal formyl group is retained but it has remained unclear, which proteins these are. A recent proteomic study has shown by $2 \mathrm{D}$ gel electropheresis that the majority of proteins in Bacillus subtilis are deformylated but that a substantial number of proteins retain the formyl group [15].

In an attempt to elucidate how the absence of formylated proteins impacts on the metabolic capacities of bacteria the exometabolomes, abilities to catabolize specific nutrients, and susceptibilities to inhibitors of the folic acid metabolisms of $S$. aureus wild type and fint mutant strains were compared. The results indicate that formylated proteins are required for distinct metabolic pathways including the anaerobic degradation of arginine via the arginine deiminase pathway and the oxidation of pyruvate. Moreover, the fmt mutant was more susceptible to trimethoprim and sulfamethoxazole indicating that the folic acid metabolism was perturbed in the mutant.

\section{Results}

Reduced growth of the S. aureus $\Delta$ fmt mutant in the presence of oxygen

The fmt gene is not essential for viability but its inactivation compromises growth in several bacterial species $[3,4,16]$. In order to analyze under which conditions fmt inactivation affects growth of $S$. aureus the multiplication of RN4220 wild type, fmt mutant ( $\Delta f m t)$, and complemented mutant was monitored under aerated and non-aerated growth conditions. In the presence of oxygen $\Delta f m t$ exhibited a significantly reduced growth rate compared to wild type and complemented mutant and reached slightly lower densities after $24 \mathrm{~h}$ of growth (Figure 1A). Under anaerobic conditions growth of all three strains was similar and the mutant exhibited significantly lower densities only at the $4 \mathrm{~h}$ time point (Figure 1B).

It can be assumed that the growth defect of $\Delta f m t$ results largely from inactivity of proteins whose function may depend on $\mathrm{N}$-terminal formylation. In order to
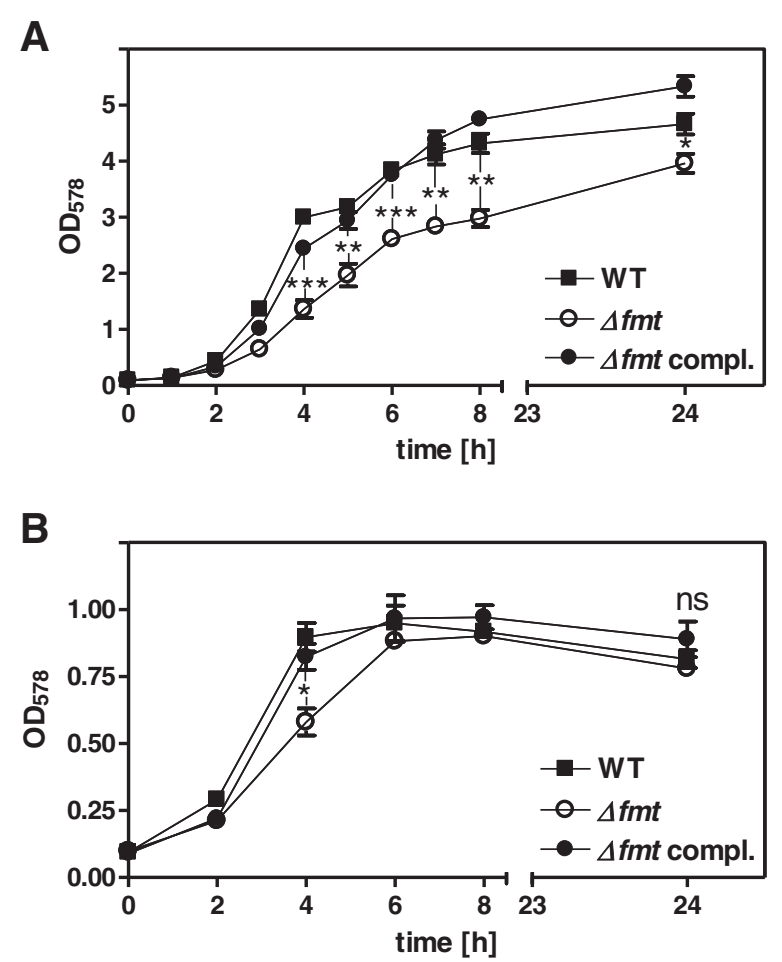

Figure 1 Growth of $\Delta f m t$ mutant, wild type, and complemented $\Delta$ fmt mutant in BM under (A) aerated and (B) anaerobic conditions. Data represent means \pm SEM of three independent experiments. Significances of wild type vs. $\Delta$ fmt: ${ }^{*} P<0.05$; ${ }^{* *} P<0.005$; ${ }^{* *} P<0.001$; ns not significant; as calculated with the two-tailed Student's t-test.

elucidate how the absence of protein formylation may impact on global gene expression microarray analysis was performed with the wild-type and mutant strains. This experiment proved the absence of the fint gene and showed that polypeptide deformylase, which has no substrates in the mutant is downregulated in $\Delta f m t$ (Table 1). In addition, genes from several metabolic pathways were downregulated in $\Delta f m t$ indicating that the absence of formylated proteins has pleiotrophic effects on transcription, which results probably either from dysfunctional regulatory proteins or from regulatory feedback events in metabolic pathways depending on formylated enzymes (see below).

\section{Absence of formylated proteins results in abrogated pyruvate metabolism}

In order to analyze how fmt inactivation affects global metabolic processes the exometabolomes of wild-type and $\Delta f m t$ strains in aerated cultures were compared by ${ }^{1} \mathrm{H}-\mathrm{NMR}$ in the exponential and stationary growth phases. $\Delta f m t$ consumed glucose much less efficiently than the wild type during the exponential growth phase, which is in agreement with the slower multiplication of the mutant but glucose was completely spent by both 
Table 1 Genes involved in metabolic processes differentially regulated by fmt deletion in S. aureus RN4220 under (A) aerobic or (B) anaerobic growth conditions

\begin{tabular}{|c|c|c|}
\hline $\begin{array}{l}\text { Gene } \\
I D^{a, b}\end{array}$ & Name $^{b}$ Gene product ${ }^{b}$ & $\begin{array}{l}\text { x-fold } \\
\text { change }\end{array}$ \\
\hline
\end{tabular}

\section{Reduced expression in $\Delta f m t$ compared to wild type:}

Amino acid metabolism

\begin{tabular}{|c|c|c|c|}
\hline 01452 & ald & alanine dehydrogenase & 103.1 \\
\hline 00008 & hutH & histidine ammonia-lyase & 67.1 \\
\hline 01451 & ilvA & threonine dehydratase & 39.8 \\
\hline 00899 & $\arg G$ & argininosuccinate synthase & 22.5 \\
\hline 00435 & gltB & glutamate synthase, large subunit, putative & 21.8 \\
\hline 02468 & alss & acetolactate synthase & 14.1 \\
\hline 00558 & & acetyl-CoA acetyltransferase, putative & 12.2 \\
\hline 01497 & ans A & L-asparaginase, putative & 7.6 \\
\hline 01450 & & amino acid permease* & 6.4 \\
\hline 00081 & & HPCH-HPAl aldolase family protein* & 4.6 \\
\hline 02287 & leuC & $\begin{array}{l}\text { 3-isopropylmalate dehydratase, large } \\
\text { subunit }\end{array}$ & 4.4 \\
\hline 02574 & & $\begin{array}{l}\text { NAD-NADP octopine-nopaline } \\
\text { dehydrogenase family protein* }\end{array}$ & 3.8 \\
\hline 01450 & & amino acid permease* & 3.2 \\
\hline 02281 & $i / v D$ & dihydroxy-acid dehydratase & 3.2 \\
\hline 02839 & & $\begin{array}{l}\text { L-serine dehydratase, iron-sulfur- } \\
\text { dependent, alpha subunit }\end{array}$ & 2.9 \\
\hline 00510 & CysE & serine acetyltransferase, putative & 2.8 \\
\hline 00147 & & acetylglutamate kinase, putative & 2.5 \\
\hline 02563 & ureF & urease accessory protein, putative & 2.3 \\
\hline 02723 & & glycerate kinase, putative & 2.2 \\
\hline
\end{tabular}

Protein biosynthesis

\begin{tabular}{llll}
\hline 01183 & fmt & methionyl tRNA formyltransferase & 585.8 \\
\hline 01182 & def2 $^{*}$ & polypeptide deformylase $\left(\right.$ def2 ${ }^{*}$ ) & 6.3 \\
\hline 01839 & tyrs & tyrosyl-tRNA synthetase & 2.8 \\
\hline 00324 & & $\begin{array}{l}\text { ribosomal-protein-serine acetyltransferase, } \\
\text { putative }\end{array}$ & 2.4 \\
\hline 01738 & his & histidyl-tRNA synthetase & 2.4
\end{tabular}

\begin{tabular}{llll}
\hline 01738 & hisS & histidyl-tRNA synthetase & 2.4 \\
\hline \multicolumn{2}{l}{ Folic acid metabolism } \\
\hline 01183 fmt & methionyl tRNA formyltransferase & 585.8 \\
\hline 02374 & $\begin{array}{l}\text { aminobenzoyl-glutamate utilization protein } \\
\text { B, putative }\end{array}$ & 4.5 \\
\hline 02610 & hutG & formiminoglutamase & 3.4 \\
\hline Fermentation & \\
\hline 00188 & pflA & $\begin{array}{l}\text { formate acetyltransferase activating } \\
\text { enzyme }\end{array}$ & 604.5 \\
\hline 02830 & ddh & D-lactate dehydrogenase, putative & 263.6 \\
\hline 00187 & pflB & $\begin{array}{l}\text { formate acetyltransferase (pyruvate- } \\
\text { formate-lyase) }\end{array}$ & 99.0 \\
\hline 00608 & adh1 & alcohol dehydrogenase I, putative & 74.0 \\
\hline 00113 & adhE & alcohol dehydrogenase, iron-containing & 40.8 \\
\hline 02467 & budA2 & alpha-acetolactate decarboxylase & 2.6 \\
\hline
\end{tabular}

Table 1 Genes involved in metabolic processes differentially regulated by fmt deletion in S. aureus RN4220 under (A) aerobic or (B) anaerobic growth conditions (Continued)

\begin{tabular}{|c|c|c|}
\hline 02875 & L-lactate dehydrogenase, putative & 2.3 \\
\hline \multicolumn{3}{|c|}{ Purine metabolism } \\
\hline 02553 & $\begin{array}{l}\text { inosine-uridine preferring nucleoside } \\
\text { hydrolase* }\end{array}$ & 3.3 \\
\hline 00211 & $\begin{array}{l}\text { inosine-uridine preferring nucleoside } \\
\text { hydrolase* }\end{array}$ & 3.3 \\
\hline \multicolumn{3}{|c|}{ Lipid biosynthesis } \\
\hline $01278 \mathrm{~g} / \mathrm{pD}$ & $\begin{array}{l}\text { aerobic glycerol-3-phosphate } \\
\text { dehydrogenase }\end{array}$ & 14.7 \\
\hline \multicolumn{3}{|c|}{ Transport systems } \\
\hline 00748 & $\begin{array}{l}\text { iron compound ABC transporter, ATP- } \\
\text { binding protein, putative* }\end{array}$ & 15.0 \\
\hline 03019 & $\begin{array}{l}\text { ABC transporter, ATP-binding protein, } \\
\text { putative }\end{array}$ & 7.2 \\
\hline 01991 & $\begin{array}{l}\text { ABC transporter, permease protein, } \\
\text { putative }\end{array}$ & 7.1 \\
\hline 00155 & PTS system, glucose-specific component & 5.0 \\
\hline 00424 & $\begin{array}{l}\text { ABC transporter, permease protein, } \\
\text { putative }\end{array}$ & 3.9 \\
\hline 02154 & $\begin{array}{l}\text { ABC transporter, ATP-binding protein, } \\
\text { putative }\end{array}$ & 2.6 \\
\hline 00844 & ABC transporter, substrate-binding protein* & 2.2 \\
\hline 00215 & PTS system component, putative & 2.1 \\
\hline \multicolumn{3}{|c|}{$\underline{\text { Urea metabolism }}$} \\
\hline $00899 \arg G$ & argininosuccinate synthase & 22.5 \\
\hline 02563 ureF & urease accessory protein, putative & 2.3 \\
\hline \multicolumn{3}{|c|}{ energy production and conversion/electrone transfer } \\
\hline $00412 \quad n d h F$ & NADH dehydrogenase subunit 5, putative & 359.0 \\
\hline 00302 & $\begin{array}{l}\text { NADH-dependent flavin oxidoreductase, } \\
\text { Oye family* }\end{array}$ & 5.2 \\
\hline
\end{tabular}

\section{Higher expression in $\Delta f m t$ compared to wild type:}

Amino acid metabolism

\begin{tabular}{llll}
\hline 02971 & aur & aureolysin, putative & 3.4 \\
\hline B & & \\
\hline $\begin{array}{l}\text { Gene } \\
\text { ID }^{\mathbf{a}, \mathbf{b}}\end{array}$ & Name $^{\mathbf{b}}$ & Gene product $^{\mathbf{b}}$ & $\begin{array}{l}\text { x-fold } \\
\text { change }\end{array}$ \\
\hline
\end{tabular}

Reduced expression in $\Delta$ fmt compared to wild type:

Amino acid metabolism

\begin{tabular}{llll}
\hline 00836 & gcvH & glycine cleavage system H protein & 2.4 \\
\hline 00151 & & $\begin{array}{l}\text { branched-chain amino acid transport } \\
\text { system II carrier protein }\end{array}$ & 2.4 \\
\hline 01452 & ald & alanine dehydrogenase & 2.3 \\
\hline 01450 & & amino acid permease & 2.1 \\
\hline 00510 & cysE & serine acetyltransferase, putative & 2.1 \\
\hline 01451 & ilvA & threonine dehydratase & 2.1 \\
\hline Protein biosynthesis & \\
\hline 01183 & fmt & methionyl-tRNA formyltransferase & 158.3 \\
\hline 01182 & def2 & polypeptide deformylase (def2 & \\
\hline 01788 & thr $S$ & threonyl-tRNA synthetase & 4 \\
\hline
\end{tabular}




\section{Table 1 Genes involved in metabolic processes differentially regulated by fmt deletion in S. aureus RN4220 under (A) aerobic or (B) anaerobic growth conditions (Continued)}

\begin{tabular}{llll}
\hline 00009 & serS & seryl-tRNA synthetase & 2.4 \\
\hline 01839 & tyrS & tyrosyl-tRNA synthetase & 2.3 \\
\hline 01159 & ilss & isoleucyl-tRNA synthetase & 2.1 \\
\hline
\end{tabular}

Folic acid metabolism

\begin{tabular}{llll}
\hline $01183 \quad \mathrm{fmt}$ & methionyl-tRNA formyltransferase & 158.3 \\
\hline $00836 \quad$ gcvH & glycine cleavage system H protein & 2.4 \\
\hline Lipid biosynthesis & \\
\hline $01310 \quad$ cardiolipin synthetase, putative & 2.8 \\
\hline
\end{tabular}

Fermentation

\begin{tabular}{|c|c|c|}
\hline 02830 ddh & D-lactate dehydrogenase, putative & 9.8 \\
\hline 00206 & L-lactate dehydrogenase & 2.3 \\
\hline 00113 adhE & alcohol dehydrogenase, iron-containing & 2 \\
\hline \multicolumn{3}{|c|}{ Increased expression in $\Delta f m t$ compared to wild type: } \\
\hline \multicolumn{3}{|c|}{ Amino acid metabolism } \\
\hline 02840 & $\begin{array}{l}\text { L-serine dehydratase, iron-sulfur- } \\
\text { dependent, beta subunit }\end{array}$ & 4.3 \\
\hline
\end{tabular}

Protein biosynthesis

\begin{tabular}{|c|c|c|c|}
\hline 01725 & & tRNA methyl transferase, putative & 2.1 \\
\hline \multicolumn{4}{|c|}{ Purine metabolism } \\
\hline 01012 & purQ & $\begin{array}{l}\text { phosphoribosylformylglycinamidine } \\
\text { synthase I }\end{array}$ & 4.2 \\
\hline 01014 & purF & amidophosphoribosyltransferase & 3.6 \\
\hline 00372 & xprT & xanthine phosphoribosyltransferase & 3.2 \\
\hline
\end{tabular}

Purine metabolism (continued)

\begin{tabular}{|c|c|c|c|}
\hline 00375 & guaA & GMP synthase, putative & 2 \\
\hline \multicolumn{4}{|c|}{ Lipid biosynthesis } \\
\hline 01260 & pgsA & $\begin{array}{l}\text { CDP-diacylglycerol-glycerol-3-phosphate } \\
\text { 3-phosphatidyltransferase }\end{array}$ & 2.1 \\
\hline 03006 & & lipase & 2.7 \\
\hline
\end{tabular}

Carbohydrate metabolism

\begin{tabular}{|c|c|c|c|}
\hline 01794 & gap & $\begin{array}{l}\text { glyceraldehyde-3-phosphate } \\
\text { dehydrogenase, type I }\end{array}$ & 6.3 \\
\hline 00239 & & ribokinase, putative & 2.1 \\
\hline
\end{tabular}

Riboflavin metabolism

\begin{tabular}{|c|c|c|}
\hline 01886 & riboflavin synthase, beta subunit & 25 \\
\hline 01888 & riboflavin synthase, alpha subunit & 5.7 \\
\hline 01889 ribD & riboflavin biosynthesis protein RibD & 4.5 \\
\hline
\end{tabular}

* defined for S. aureus COL;

a SAOUHSC gene ID for S. aureus NCTC8325.

${ }^{\mathrm{b}}$ Gene IDs, names and products are based on AureusDB (http://aureusdb.

biologie.uni-greifswald.de) and NCBI (http://www.ncbi.n/m.nih.gov/) annotation.

strains in the stationary phase (Figure 2). In parallel, arginine, branched-chain amino acids, and the aromatic amino acids phenylalanine and tyrosine were consumed more slowly by $\Delta f m t$ compared to the wild type during exponential growth but these differences disappeared largely in the stationary phase.
Both strains accumulated acetate, the primary catabolic product of S. aureus in aerated cultures [17] at similar levels and there were also no major differences found for the citric acid cycle intermediates 2-oxoglutarate, succinate, and fumarate. These findings suggested that central catabolic pathways downstream of acetyl-CoA were not affected by the lack of formylation in $\Delta f m t$.

Of note, $\Delta f m t$ released more of the central metabolic intermediate pyruvate to the growth medium than the wild type in the stationary phase suggesting that the metabolism of pyruvate was perturbed in the absence of protein formylation. Pyruvate and acetyl CoA-derived fermentation products including acetoin, butanediol, ethanol, and lactate were produced by both strains indicating that growth conditions were not fully aerobic (Figure 2). However, $\Delta f m t$ produced considerably lower amounts of acetoin and lactate than the wild type, in particular in the stationary phase, which was paralleled by reduced expression of acetolactate decarboxylase and of two lactate dehydrogenases that lead to acetoin and lactate generation, respectively, from pyruvate (Table 1, Figure 2). Both strains produced alanine, which is generated from pyruvate by alanine dehydrogenase Ald, in the stationary phase. However, $\Delta f m t$ produced much less alanine, which corresponded to strongly reduced ald transcription in the mutant. Transcription of the four subunits of the pyruvate dehydrogenase complex PdhABCD was unaltered indicating that this major pyruvate-oxidizing enzyme linking glycolysis with the citric acid cycle should be present at similar amounts in wild type and $\Delta f m t$. However, when cytoplasmic PdhABCD activity was compared the mutant exhibited ca. $20 \%$ lower activity than the wild type and complemented mutant $(108 \mathrm{mU} / \mathrm{mg}$ protein vs. $133 \mathrm{mU} / \mathrm{mg}$ and $124 \mathrm{mU} / \mathrm{mg}$, respectively) suggesting that in addition to reduced fermentative pyruvate reduction a lower pyruvate oxidation rate may contribute to increased pyruvate accumulation in the mutant. In agreement with these findings $\Delta f m t$ was found to have a higher molecular $\mathrm{NAD}^{+} / \mathrm{NADH}$ ratio compared to the wild-type strain (37.5 vs. 22.0, respectively). This difference may be a reason for some of the observed differences in expression of genes such as lactate dehydrogenase or alanine dehydrogenase, whose transcription is controlled by the $\mathrm{NAD}^{+}$-sensing Rex repressor [18].

Microarray analyses did not reveal differences in expression of major enzymes involved in glycolysis or degradation of those amino acids that were less efficiently consumed by the mutant (Table 1). Thus, the reduced consumption of glucose or amino acids may result either from perturbed pyruvate utilization or/and from reduced activity of one or several enzymes involved in catabolic pathways upstream of pyruvate. Several genes involved in amino acid biosynthesis, protein and folic acid metabolism, and several transport systems were dysregulated in 


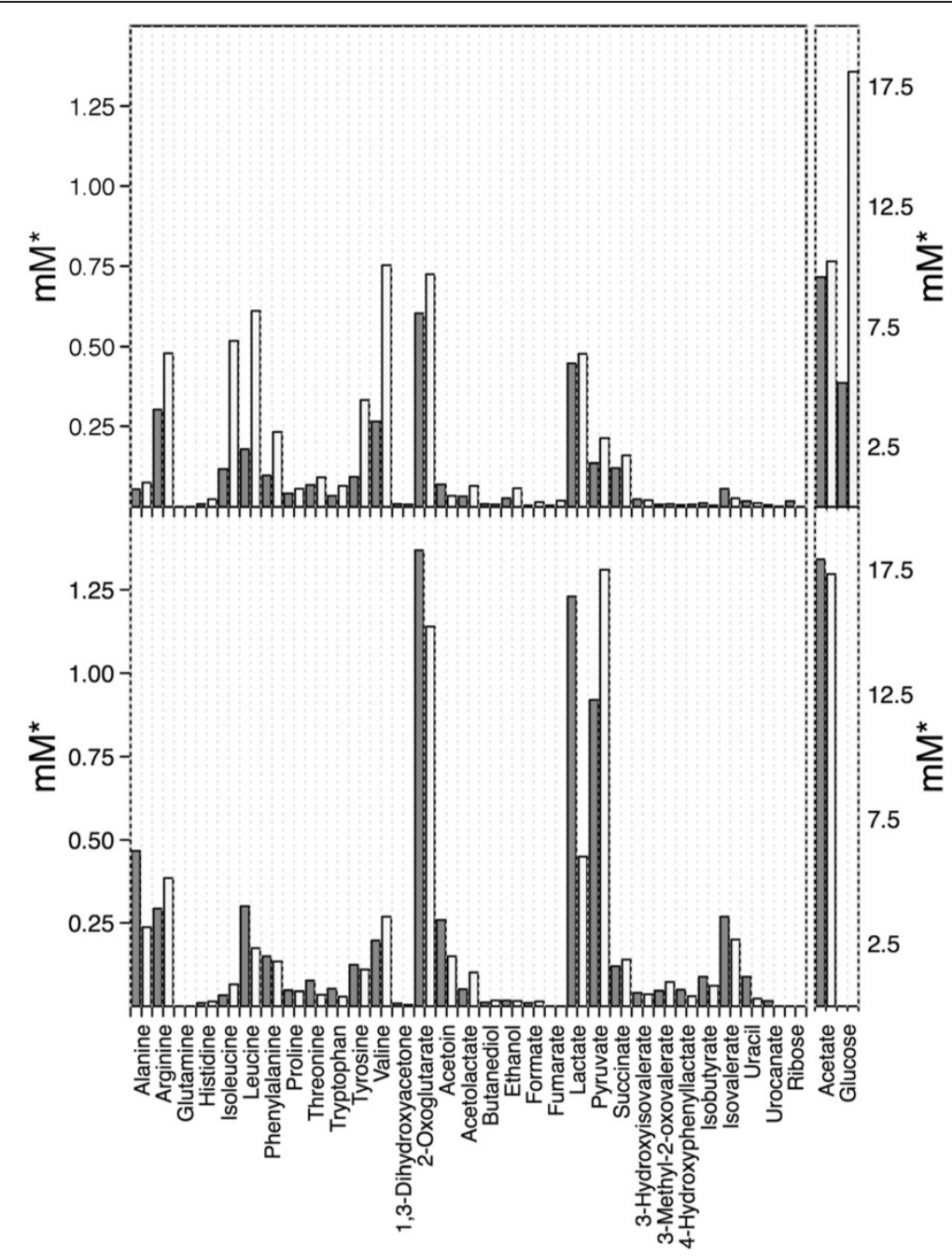

Figure 2 Exometabolome analysis of $S$. aureus wild type (gray bars) and $\Delta f m t$ mutant (white bars) grown to late exponential (top) and stationary (bottom) growth phase. ${ }^{*}$, concentrations relative to measured $A_{578}$ values at a given time point.

$\Delta f m t$, which may also contribute to the slower growth of the mutant. Transcription of a putative NADH dehydrogenase subunit $(n d h F)$ was strongly repressed in $\Delta f m t$, maybe as a result of the altered $\mathrm{NAD}^{+} / \mathrm{NADH}$ ratio. However, $\Delta f m t$ grew much better under aerated compared to non-aerated conditions (Figure 1) and it did not produce more ermentation products than the wild type (Figure 2) indicating that the respiratory capacity of the mutant remained largely intact. $\Delta f m t$ also released lower amounts of uracil than the wild-type (Figure 2) and this difference was reflected by reduced expression of uridine nucleoside hydrolase (Table 1A).

\section{Lack of arginine deiminase activity in $\Delta f m t$ mutant}

Our metabolomics approach measured only those metabolites that appeared in culture supernatants. In order to monitor further metabolic activities the wild-type, $\Delta f m t$ and complemented mutant strains were checked for the ability to catabolize different carbon and energy sources with an ApiStaph diagnostic test (BioMérieux). Only one out of 20 reactions revealed a different behavior of $\Delta f m t$ (Figure 3). No degradation of arginine via arginine deiminase (ADI) leading to the production of citrulline and ammonia was observed in $\Delta f m t$. This reaction is the first step in the anaerobic catabolism of arginine, which serves as an ATP source by substrate level phosphorylation [19]. Of note, the enzymes of the ADI pathway were not altered in their expression, neither under aerobic nor anaerobic conditions (Table 1) suggesting that the absence of formylation may directly affect the activity of one or more ADI pathway enzymes.

\section{fmt inactivation leads to increased susceptibility to trimethoprim and sulfamethoxazole}

In order to analyse if the block in formyl transfer from 10-CHO-THF to the initiator tRNA impacts on 


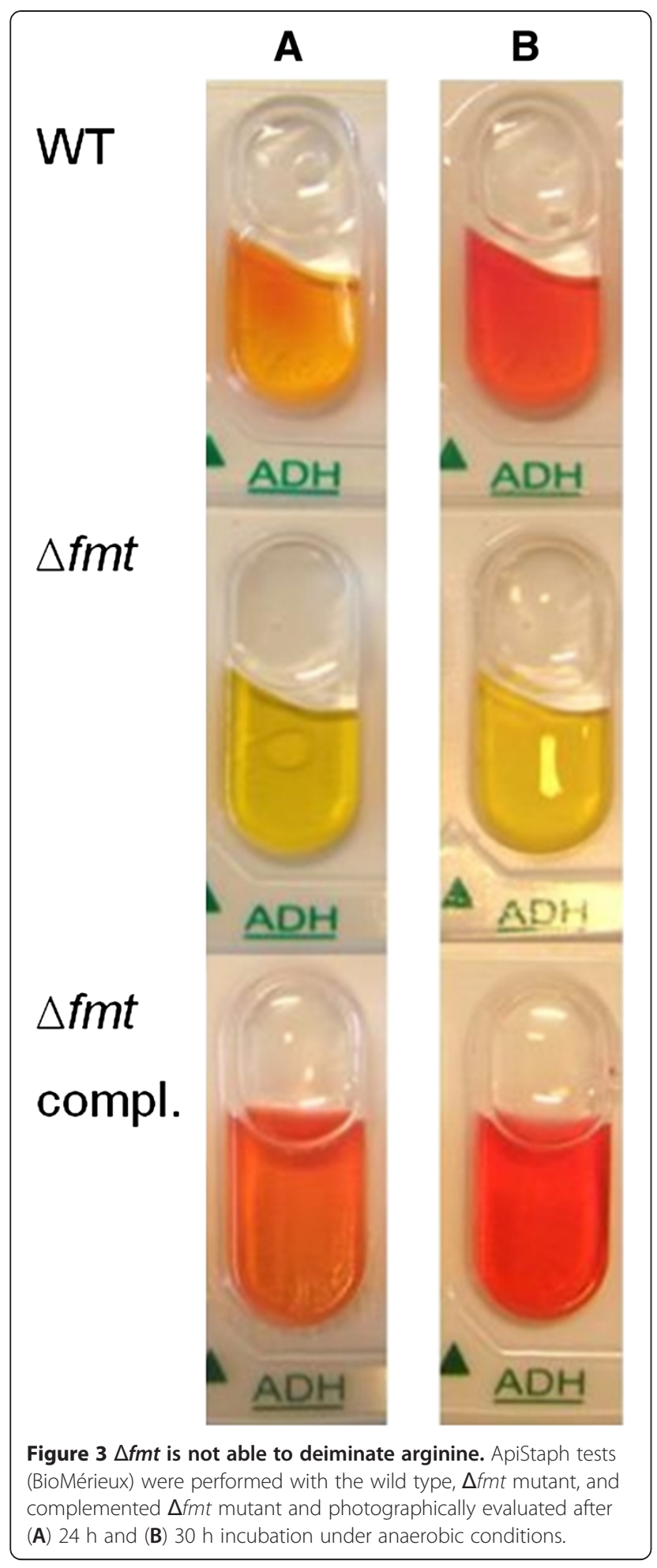

susceptibility to inhibitors of folic acid metabolic processes the abilities of trimethoprim and sulfamethoxazole, antagonists of dihydrofolate reductase and dihydropteroate synthetase, respectively [20], to inhibit $S$. aureus with or without functional Fmt were compared. In fact, the
MICs of trimethoprim and sulfamethoxazole were 3.5-fold and 3-fold lower, respectively, in $\Delta f m t$ compared to the parental strain (Figure 4). Complementation with a plasmid-encoded copy of fimt led to partially or fully restored MICs indicating that the increased susceptibility of $\Delta f m t$ was in fact a result of lacking formylated proteins. No changes in expression of genes for key enzymes directly involved in the folic acid pathway were observed (Table 1) indicating that the proteins should be produced in equal amounts but may differ in activities leading to altered metabolic fluxes and corresponding differences in antagonist susceptibilities.

\section{Discussion}

Our study demonstrates that the lack of start tRNA ormylation has pleiotropic consequences and affects the global S. aureus exometabolome and transcriptome in multiple ways. Protein N-termini are usually positively charged but formylated amino groups cannot be protonated any more, which can alter protein conformation and function substantially. We expected that protein dysfunction resulting from $\mathrm{N}$-terminal charge alteration may affect cellular functions in multiple ways including e.g. by compromising the function of structural proteins, regulators, or enzymes leading to global cellular stress responses, altering regulatory networks, or perturbing metabolic pathways, respectively. It has remained unclear, which $S$. aureus proteins retain formyl groups upon translation and the activity of which of these may depend on formylation. Our approach set out to assess, which metabolic processes may be compromised in a fmt mutant and we found that many exometabolites were present at similar levels in the wild-type and $\Delta f m t$ strains while the catabolism of glucose and certain amino acids, the release of pyruvate or pyruvatederived fermentation products, and the susceptibility to inhibitors of enzymes depending on folic acid derivatives was changed. Thus, protein formylation has distinct roles in certain metabolic pathways. The reduced catabolism of glucose and branched-chain and aromatic amino acids by $\Delta f m t$ was not reflected by changes in transcription of genes for corresponding enzymes suggesting that these changes did not result from perturbed gene regulation but from compromised abilities of $S$. aureus to degrade these nutrients. Likewise, the anaerobic degradation of arginine by the ADI pathway was abolished in $\Delta f m t$ while transcription of the corresponding genes appeared to be unchanged. It remains unclear, which of the many catabolic enzymes may be affected by the lack of $\mathrm{N}$-terminal protein formylation. Moreover, we noted that transcription of some transport proteins of unknown function was reduced in $\Delta f m t$ and it cannot be ruled out that one or several of these may be required for amino acid uptake. 

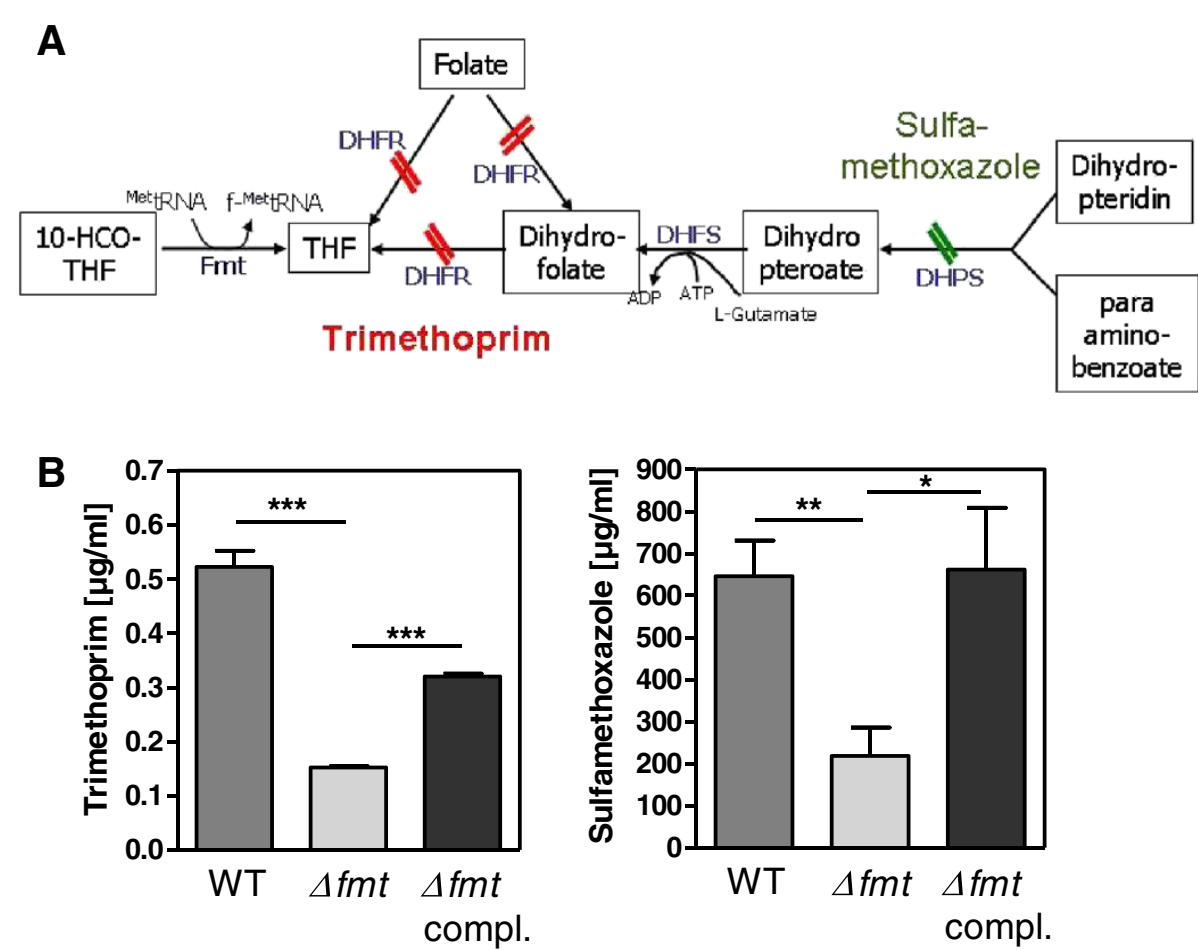

Figure 4 Impact of $\Delta f m t$ mutation on the folic acid pathway. (A) Consequences on folic acid metabolism of dihydrofolate reductase (DHFR) inhibition with trimethoprim and dihydropteroate synthetase (DHPS) inhibition with sulfamethoxazole. DHFS stands for dihydrofolate synthase. (B) MICs were determined for the indicated antibiotics. Data represent means \pm SEM of at least three independent experiments. ${ }^{*} P<0.05$; ${ }^{* *} P<0.005 ;{ }^{* *} P<0.001$ as calculated by the two-tailed Student's $t$-test.

Extracellular accumulation of the central metabolic intermediate pyruvate was much more pronounced in $\Delta f m t$ than in the wild type, which was accompanied by reduced production of pyruvate-derived alanine and fermentation products acetoin and lactate. The production of fermentation products suggests that our cultivation conditions were not fully aerobic. The concomitantly reduced transcription of alanine dehydrogenase, acetolactate decarboxylase, and lactate dehydrogenases suggests that pyruvate accumulation may be a result of transcriptional repression of fermentative pathways in $\Delta f m t$ the reasons for which remain unknown and may result e.g. from altered activity of metabolic regulators such as the $\mathrm{NAD}^{+}$-sensing Rex [18]. However, the specific activity of the pyruvate-oxidizing PDHC was also reduced in the mutant, which is in accord with the increased $\mathrm{NAD}^{+} / \mathrm{NADH}$ ratio in the mutant and our recent finding that inhibition of $S$. aureus PDHC leads to accumulation of extracellular pyruvate [21]. Since transcription of the PDHC-encoding genes pdhABCD was unaltered in $\Delta f m t$ its reduced PDHC activity may indicate that one or several proteins of PdhABCD may require a formylated $\mathrm{N}$-terminus for full activity.

Since inactivation of Fmt should lead to increased amounts of formyl THF and reduced amounts of free
THF in $\Delta f m t$ we proposed that the mutant should have altered susceptibility to antibiotics that block the de novo synthesis of THF. In fact, $\Delta f m t$ was more susceptible to trimethoprim and sulfamethoxazole than the wild type, which indicates that the folic acid metabolism was perturbed by fmt inactivation and suggests that the availability of THF derivatives that are e.g. necessary for purine biosynthesis becomes growthlimiting at lower antibiotic concentrations as in the wild type.

\section{Conclusions}

Our study shows that the lack of protein formylation does not abrogate all kinds of metabolic activities but has particular impacts in certain pathways. Elucidating, which specific enzymes or regulators may lose their activity by the lack of formylation remains a challenging aim. Our approach will be of importance for defining individual metabolic pathways depending on formylated proteins and it represents a basis for more detailed studies. Addressing these questions will not only be of importance for understanding a central bacterial process, it may also help to identify new antibiotic targets and further elucidate the importance of formylated peptides in innate immune recognition. 


\section{Methods}

\section{Bacterial strains and growth}

S. aureus RN4220 and the previously described RN4220 fint mutant [4] along with the plasmid-complemented mutant [7] were used in this study. In order to compare growth kinetics basic medium (BM) composed of $1 \%$ casein peptone, $0.5 \%$ yeast extract, $0.5 \% \mathrm{NaCl}, 0.1 \%$ $\mathrm{K}_{2} \mathrm{HPO}_{4} \times 3 \mathrm{H}_{2} 0$, and $0.1 \%$ glucose was inoculated with bacterial over-night cultures grown in tryptic soy broth (TSB; Fluka) at an $\mathrm{OD}_{578}$ of 0.08 and cultivated either with aeration $(50 \mathrm{ml}$ in notched $100 \mathrm{ml}$ flasks on a shaker) or without (completely filled, sealed $15 \mathrm{ml}$ tubes) at $37^{\circ} \mathrm{C}$ and $\mathrm{OD}_{578}$ was measured at several time points. Cultures of the complemented mutant were supplemented with $10 \mu \mathrm{g} / \mathrm{ml}$ chloramphenicol. To compare capacities to catabolize various substrates the various strains were used to inoculate ApiStaph tubes (BioMérieux), which were incubated and evaluated according to the manufacturers' manual.

\section{Extracellular metabolome analysis by ${ }^{1} \mathrm{H}-\mathrm{NMR}$}

For quantification of extracellular metabolites TSB overnight cultures of RN4220 wild type and the $\Delta f m t$ mutant were used to inoculate $100 \mathrm{ml}$ Iscove's modified Dulbecco's media (IMDM) without phenol red (Gibco) in notched $250 \mathrm{ml}$ flasks at an $\mathrm{OD}_{578}$ of 0.1 . The cultures were incubated on a shaker at $37^{\circ} \mathrm{C}$. Samples were taken at $8 \mathrm{~h}$ and $24 \mathrm{~h}$ to determine the $\mathrm{OD}_{578}$ and obtain culture supernatants by centrifugation with subsequent filtration $(0.22 \mu \mathrm{m}$ pore size). Samples were prepared and analyzed by ${ }^{1} \mathrm{H}-\mathrm{NMR}$ as described recently [21,22]. Briefly, $400 \mu \mathrm{l}$ of supernatants were mixed with $200 \mu$ l phosphate buffer $(0.2 \mathrm{M}$; pH 7.0) and applied to a Bruker ${ }^{\circledR}$ Avance II $600 \mathrm{MHz}$ spectrometer operating with TOPSPIN 2.0 (Bruker ${ }^{\circledR}$ Biospin). Metabolites were identified by comparison with pure reference compound spectra. Trimethylsilylpropionic acid $\mathrm{d}_{4}$ was used as internal standard. All spectra were processed in Chenomx NMR Suite 4.6 (Chenomx, Edmonton, AB, Canada) and selected metabolites were quantified by computer-assisted manual fitting of metabolite peaks.

\section{RNA isolation and microarray analyses}

To compare the transcription profiles of the RN4220 wild type and $\Delta f m t$ mutant the strains were grown in $\mathrm{BM}$ (13 ml in notched $50 \mathrm{ml}$ flasks) at $37^{\circ} \mathrm{C}$ to an $\mathrm{OD}_{578}$ 1.0 under aerobic conditions or to an $\mathrm{OD}_{578} 0.5$ under anaerobic conditions (completely filled and sealed $15 \mathrm{ml}$ tubes). Bacteria were harvested via centrifugation and immediately frozen at $-80^{\circ} \mathrm{C}$. Samples were then thawed on ice and resuspended with $1 \mathrm{ml}$ Trizol (Invitrogen) to inhibit RNases and bacteria were disrupted with $0.5 \mathrm{ml}$ glass bead suspension in a homogenizer. The supernatants of these lysates were mixed with $200 \mu \mathrm{l}$ chloroform for $60 \mathrm{~s}$ and incubated for another three minutes to extract the RNA. After centrifugation (15 min; 12,000 × g; $4^{\circ} \mathrm{C}$ ) the upper phase was collected and pipetted into $500 \mu \mathrm{l}$ isopropanole. After $10 \mathrm{~min}$ at room temperature the samples were centrifuged for $30 \mathrm{~min}$ again to collect supernatants. Then $500 \mu \mathrm{l} 70 \%$ ethanol was added and the samples were centrifuged at $4^{\circ} \mathrm{C}, 7,500 \times \mathrm{g}$ for $5 \mathrm{~min}$. After removing the supernatants pellets were dried for about $1 \mathrm{~h}$, dissloved in $500 \mu \mathrm{l}$ sodium citrate buffer, and further purified with a Microcon filter cartridge (Millipore) and stored at $-80^{\circ} \mathrm{C}$. Each $10 \mu \mathrm{g}$ of RNA from two biological replicates per condition and strain were applied to GeneChip microarrays (Affymetrix) and processed according to the manufacturer's protocol. The biological replicates yielded highly reproducible expression profiles, which were deposited at the GEO data base (http://www.ncbi.nlm.nih.gov/geo/) with accession number GSE41713.

\section{Pyruvate dehydrogenase complex (PDHC) activity}

$S$. aureus cells grown in BM to late exponential phase were resuspended in phosphate buffer $(0.2 \mathrm{M}, \mathrm{pH} 7.4)$ and disrupted by a combined enzymatic (lysostaphin) and mechanical (glass bead mill) procedure in the presence of DNase I as described recently in detail [21]. Insoluble components were removed from the extracts by centrifugation $\left(14,000 \times g\right.$ for $10 \mathrm{~min}$ at $\left.4^{\circ} \mathrm{C}\right)$ and $4 \times 500 \mu \mathrm{l}$ of the resulting filter-sterilized lysate were subjected to ultracentrifugation for $1 \mathrm{~h}$ using a Beckman TLA-55 rotor at 50,000 rpm and $4^{\circ} \mathrm{C}$ to enrich PDHC. Reaction mixtures for determining PDHC activity contained $0.2 \mathrm{M}$ phosphate buffer, $0.2 \mathrm{mM} \mathrm{MgCl}_{2}$, $0.01 \mathrm{mM} \mathrm{CaCl}_{2}, \quad 0.3 \mathrm{mM}$ thiamine diphosphate, $0.12 \mathrm{mM}$ coenzyme A (CoA), $2.0 \mathrm{mM} ß-\mathrm{NAD}^{+}, 5.1 \mathrm{mM}$ pyruvate, $0.1 \mathrm{mM}$ 1-methoxy-5-methylphenazinium methyl sulphate (mPMS), and $0.4 \mathrm{mM}$ iodonitrotetrazolium formazan in an assay volume of $1.5 \mathrm{ml}$. Enzymatic activity was measured spectrophotometrically at $500 \mathrm{~nm}$ and $20^{\circ} \mathrm{C}$ as described recently [21]. Units of activity were calculated using a molar absorption coefficient of $12.5 \mathrm{mM}^{-1} \mathrm{~cm}^{-1}$.

\section{$\mathrm{NAD}^{+} / \mathrm{NADH}$ quantification}

To measure alterations in the $\mathrm{NAD}^{+} / \mathrm{NADH}$ ratio between RN4220 wild type and $\Delta f m t$ the strains were grown in $\mathrm{BM}$ at $37^{\circ} \mathrm{C}$ to an $\mathrm{OD}_{578}$ of 1.0 under aerobic conditions. The $\mathrm{NAD}^{+} / \mathrm{NADH}$ Quantification Kit (BioVision) was used and processed according to the manufacturer's protocol with some modifications. Briefly, $25 \mathrm{ml}$ of the cultures were harvested by centrifugation and pellets were resuspended in $400 \mu \mathrm{l}$ of NADH/NAD extraction buffer. Extracts were obtained by homogenizing the resuspended pellets with $0.5 \mathrm{ml}$ glass bead suspension. After centrifugation the 
supernatants were filtered through $10 \mathrm{kDa}$ molecularweight cut-off filters (BioVision). Ratios were calculated as [total NAD minus NADH]/NADH.

\section{Minimal inhibitory concentration of antibiotics}

To define differences in the susceptibility to trimethoprim and sulfamethoxazole (Sigma) over-night cultures of RN4220 wild type, $\Delta f m t$, and the complemented mutant were used to inoculate $500 \mu \mathrm{l}$ IMDM without phenol red (Gibco) to an $\mathrm{OD}_{578}$ of 0.1 in 24-well plates (Costar) containing serially diluted antibiotics in duplicates. After 18 hours incubation at $37^{\circ} \mathrm{C}$ under gentle agitation the densities were measured to determine minimal inhibitory concentrations.

\section{Competing interests}

The authors declare to have no competing interests.

\section{Authors' contributions}

DM, MLi, WW, KM, ML performed the experiments; FG, MLa, AP conceived the study; AP wrote the manuscript. All authors read and approved the final manuscript.

\section{Acknowledgments}

This work was financed by the German Research Foundation (DFG) grants TRR34 to A.P., M.La, and F.G., the German Ministry of Education and Research (SkinStaph, Menage) to A.P.; and a fellowship from the Alfried Krupp von Bohlen Halbach-Stiftung: "A Functional Genomics Approach in Infection Biology" to M.Li. The authors acknowledge support by German Research Foundation and Open Access Publishing Fund of Tübingen University.

\section{Author details}

${ }^{1}$ Interfaculty Institute of Microbiology and Infection Medicine Tübingen, Cellular and Molecular Microbiology, University of Tübingen,

Elfriede-Aulhorn-Straße 6, 72076, Tübingen, Germany. ' Institute of Pharmacy, University of Greifswald, Friedrich-Ludwig-Jahn Straße 17, 17487, Greifswald, Germany. ${ }^{3}$ Interfaculty Institute of Microbiology and Infection Medicine, Microbial Genetics, University Tübingen, Waldhäuser Strasse 70/8, Tübingen 72076, Germany. ${ }^{4}$ Current address: Biomolecular Medicine, Department of Surgery and Cancer, Faculty of Medicine, Imperial College London, London SW7 2AZ, UK.

Received: 10 May 2012 Accepted: 11 January 2013

Published: 16 January 2013

\section{References}

1. Clark BF, Marcker KA: The role of N-formyl-methionyl-sRNA in protein biosynthesis. J Mol Biol 1966, 17(2):394-406.

2. Anderson WF, Bosch L, Gros F, Grunberg-Manago M, Ochoa S, Rich A, Staehelin T: Initiation of protein synthesis in prokaryotic and eukaryotic systems. Summary of EMBO Workshop. FEBS Lett 1974, 48(1):1-6.

3. Newton DT, Creuzenet C, Mangroo D: Formylation is not essential for initiation of protein synthesis in all eubacteria. J Biol Chem 1999, 274(32):22143-22146.

4. Margolis PS, Hackbarth CJ, Young DC, Wang W, Chen D, Yuan Z, White R, Trias J: Peptide deformylase in Staphylococcus aureus: resistance to inhibition is mediated by mutations in the formyltransferase gene. AntimicrobAgents Chemother 2000, 44:1825-1831.

5. Fu H, Karlsson J, Bylund J, Movitz C, Karlsson A, Dahlgren C: Ligand recognition and activation of formyl peptide receptors in neutrophils. J Leukoc Biol 2006, 79(2):247-256.

6. Ye RD, Boulay F, Wang JM, Dahlgren C, Gerard C, Parmentier M, Serhan CN, Murphy PM: International Union of Basic and Clinical Pharmacology. LXXIII. Nomenclature for the formyl peptide receptor (FPR) family. Pharmacol Rev 2009, 61(2):119-161.

7. Dürr MC, Kristian SA, Otto M, Matteoli G, Margolis PS, Trias J, Van Kessel KP, Van Strijp JA, Bohn E, Landmann R, et al: Neutrophil chemotaxis by pathogen-associated molecular patterns-formylated peptides are crucial but not the sole neutrophil attractants produced by Staphylococcus aureus. Cell Microbiol 2006, 8(2):207-217.

8. Mader D, Rabiet MJ, Boulay F, Peschel A: Formyl peptide receptormediated proinflammatory consequences of peptide deformylase inhibition in Staphylococcus aureus. Microbes Infect 2010, 12(5):415-419.

9. de Haas CJ, Veldkamp KE, Peschel A, Weerkamp F, van Wamel WJ, Heezius EC, Poppelier MJ, Van Kessel KP, Van Strijp JA: Chemotaxis inhibitory protein of Staphylococcus aureus, a bacterial antiinflammatory agent. J ExpMed 2004, 199(5):687-695.

10. Adams JM, Capecchi MR: N-formylmethionyl-sRNA as the initiator of protein synthesis. Proc Natl Acad Sci U S A 1966, 55(1):147-155.

11. Leibig M, Liebeke M, Mader D, Lalk M, Peschel A, Gotz F: Pyruvate formate lyase acts as a formate supplier for metabolic processes during anaerobiosis in Staphylococcus aureus. J Bacteriol 2011, 193(4):952-962.

12. Mazel D, Pochet $S$, Marliere P: Genetic characterization of polypeptide deformylase, a distinctive enzyme of eubacterial translation. EMBO J 1994, 13(4):914-923.

13. Leeds JA, Dean CR: Peptide deformylase as an antibacterial target: a critical assessment. Curr Opin Pharmacol 2006, 6(5):445-452.

14. Hu YJ, Wei Y, Zhou Y, Rajagopalan PT, Pei D: Determination of substrate specificity for peptide deformylase through the screening of a combinatorial peptide library. Biochemistry 1999, 38(2):643-650.

15. Bandow JE, Becher D, Buttner $K$, Hochgrafe F, Freiberg C, Brotz H, Hecker M: The role of peptide deformylase in protein biosynthesis: a proteomic study. Proteomics 2003, 3(3):299-306.

16. Guillon JM, Mechulam Y, Schmitter JM, Blanquet S, Fayat G: Disruption of the gene for Met-tRNA(fMet) formyltransferase severely impairs growth of Escherichia coli. J Bacteriol 1992, 174:4294-4301.

17. Somerville GA, Said-Salim B, Wickman JM, Raffel SJ, Kreiswirth BN, Musser JM: Correlation of acetate catabolism and growth yield in Staphylococcus aureus: implications for host-pathogen interactions. Infect/mmun 2003, 71(8):4724-4732.

18. Pagels M, Fuchs S, Pane-Farre J, Kohler C, Menschner L, Hecker M, McNamarra PJ, Bauer MC, von Wachenfeldt C, Liebeke M, et al: Redox sensing by a Rex-family repressor is involved in the regulation of anaerobic gene expression in Staphylococcus aureus. Mol Microbiol 2010, 76(5):1142-1161.

19. Galkin A, Kulakova L, Sarikaya E, Lim K, Howard A, Herzberg O: Structural insight into arginine degradation by arginine deiminase, an antibacterial and parasite drug target. J Biol Chem 2004, 279(14):14001-14008.

20. Hitchings $\mathrm{GH}$ : Mechanism of action of trimethoprim-sulfamethoxazole. I. J Infect Dis 1973, 128(Suppl):433-436.

21. Birkenstock T, Liebeke M, Winstel V, Krismer B, Gekeler C, Niemiec MJ, Bisswanger $H$, Lalk M, Peschel A: Exometabolome analysis identifies pyruvate dehydrogenase as a target for the antibiotic triphenylbismuthdichloride in multiresistant bacterial pathogens. J Biol Chem 2012, 287(4):2887-2895.

22. Liebeke M, Brozel VS, Hecker M, Lalk M: Chemical characterization of soil extract as growth media for the ecophysiological study of bacteria. Appl Microbiol Biotechnol 2009, 83(1):161-173.

doi:10.1186/1471-2180-13-7

Cite this article as: Mader et al:: Role of $\mathrm{N}$-terminal protein formylation in central metabolic processes in Staphylococcus aureus. BMC Microbiology 2013 13:7. 